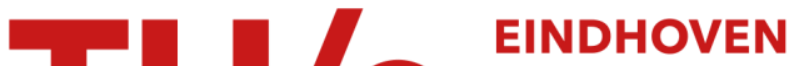 UNIVERSITY OF TECHNOLOGY
}

\section{Easily processable temperature-responsive infrared-reflective polymer coatings}

\section{Citation for published version (APA):}

Zhang, W., Kragt, S., Schenning, A. P. H. J., de Haan, L. T., \& Zhou, G. (2017). Easily processable temperatureresponsive infrared-reflective polymer coatings. ACS Omega, 2(7), 3475-3482.

https://doi.org/10.1021/acsomega.7b00454

DOI:

10.1021/acsomega.7b00454

Document status and date:

Published: 31/07/2017

\section{Document Version:}

Publisher's PDF, also known as Version of Record (includes final page, issue and volume numbers)

\section{Please check the document version of this publication:}

- A submitted manuscript is the version of the article upon submission and before peer-review. There can be important differences between the submitted version and the official published version of record. People interested in the research are advised to contact the author for the final version of the publication, or visit the $\mathrm{DOI}$ to the publisher's website.

- The final author version and the galley proof are versions of the publication after peer review.

- The final published version features the final layout of the paper including the volume, issue and page numbers.

Link to publication

\section{General rights}

Copyright and moral rights for the publications made accessible in the public portal are retained by the authors and/or other copyright owners and it is a condition of accessing publications that users recognise and abide by the legal requirements associated with these rights.

- Users may download and print one copy of any publication from the public portal for the purpose of private study or research.

- You may not further distribute the material or use it for any profit-making activity or commercial gain

- You may freely distribute the URL identifying the publication in the public portal.

If the publication is distributed under the terms of Article 25fa of the Dutch Copyright Act, indicated by the "Taverne" license above, please follow below link for the End User Agreement:

www.tue.nl/taverne

Take down policy

If you believe that this document breaches copyright please contact us at:

openaccess@tue.nl

providing details and we will investigate your claim. 


\title{
Easily Processable Temperature-Responsive Infrared-Reflective Polymer Coatings
}

\author{
Weixin Zhang, ${ }^{\dagger}$ Stijn Kragt, ${ }^{\ddagger}$ Albertus P. H. J. Schenning, ${ }^{\dagger} \ddagger \odot$ Laurens T. de Haan, ${ }^{*}{ }^{\dagger}, \S$ \\ and Guofu Zhou*, ${ }^{\dagger}, \S, \|$
}

${ }^{\dagger}$ SCNU-TUE Joint Laboratory of Device Integrated Responsive Materials (DIRM), South China Normal University, No. 378, West Waihuan Road, Guangzhou Higher Education Mega Center, 510006 Guangzhou, China

${ }^{\ddagger}$ Laboratory of Functional Organic Materials and Devices, Department of Chemical Engineering and Chemistry, Eindhoven University of Technology, P.O. Box 513, 5600 MB Eindhoven, The Netherlands

${ }^{\S}$ Shenzhen Guohua Optoelectronics Tech. Co. Ltd., No. 1301-1, Tourism Road, Dabu Xiang, Longhua District, 518110 Shenzhen, China

"Academy of Shenzhen Guohua Optoelectronics, No. 1301-1, Tourism Road, Dabu Xiang, Longhua District, Shenzhen 518110, China

\section{Supporting Information}

ABSTRACT: A temperature-responsive near-infrared reflective coating was fabricated based on a side-chain liquid crystal siloxane polymer using a simple wired-bar method. The cholesteric liquid crystalline polymer film showed a blue shift of the reflection band of $\sim 1000 \mathrm{~nm}$ in the IR region upon heating. The temperature-responsive change of the reflection band was reversible. Compared to that of the same mixture system in an alignment cell, the coating showed a significantly faster response. This research demonstrates an easy way to prepare a temperature-responsive IR-reflective coating that shifts its reflection to a shorter wavelength upon heating. As IR radiation of shorter wavelengths is more strongly represented in sunlight than longer wavelengths, this coating could be used to selectively reduce heating of an indoor space when the temperature is high. This is promising for the future application of smart climate control.

\section{INTRODUCTION}

Near-infrared (NIR) light, ranging from 700 to $2500 \mathrm{~nm}$, makes up $50 \%$ of the total sunlight energy that reaches earth and is a significant interior heating source of buildings. ${ }^{1}$ Transmission and reflection of NIR from sunlight can be regulated by specialized windows, which can reduce energy consumption for heating and cooling of buildings while still being transparent for visible light. ${ }^{2-5}$ Smart temperatureresponsive IR reflectors autonomously regulate the temperature of indoor spaces. ${ }^{6}$ As IR radiation of shorter wavelengths is more strongly represented in sunlight than longer wavelengths, ${ }^{7}$ a window that shifts its reflection to a shorter wavelength upon heating rejects more IR at higher temperatures, which reduces heating of the indoor space. If this can be done in a reversible and autonomous way, it would be a major step toward the construction of energy-neutral buildings.

Temperature-responsive photonic materials are the key to this kind of smart window, as such materials can change their reflection of light in response to temperature changes. The reflected wavelength of photonic materials, which operate as Bragg reflectors, is determined by periodic structures. The

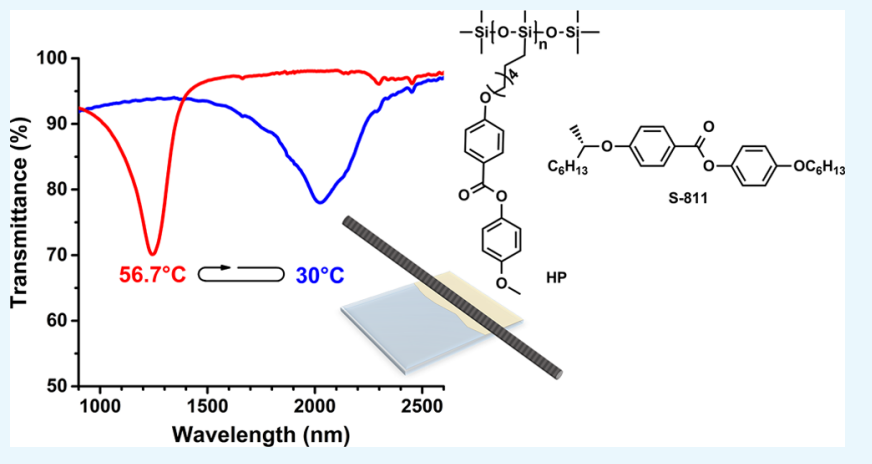

reported temperature-responsive photonic systems are based on cholesteric liquid crystals (CLCs), ${ }^{8-10}$ polymeric colloids, ${ }^{1-13}$ or thermoplastic materials. ${ }^{14-18}$ Temperatureresponsive photonic hydrogel polymer coatings have been made for temperature sensors and indicators. ${ }^{19,20}$ These hydrogel coatings rely on swelling and deswelling by water and thus require specific humidity conditions.

CLCs are an interesting category of temperature-responsive photonic materials, which can operate under dry conditions. CLCs can be obtained by introducing a chiral dopant into a nematic LC. The chiral dopant causes helical twisting of the average orientation (director) of the molecules, which induces selective Bragg-type reflection of light. As only one handedness of circular polarization is reflected, a maximum of $50 \%$ of ambient light can be reflected for a single handedness of the helix. The pitch of the helix (the distance over which the alignment director makes a $2 \pi$ rotation) in these systems

Received: April 13, 2017

Accepted: June 20, 2017

Published: July 12, 2017 
Scheme 1. (a) Chemical Structures of the LC Polysiloxane-Chiral Dopant Mixture, (b) Schematic Representation of the WiredBar Coating Method to Fabricate the Photonic Coating, and (c) Photograph of the Photonic Coating at $52{ }^{\circ} \mathrm{C}$ with a Label as Background To Show the Good Transparency in the Visible Range ${ }^{a}$<smiles>COc1ccc(OC(=O)c2ccc(OC(C)(C)CC[SiH](C)O[Si](C)(C)C)cc2)cc1</smiles>

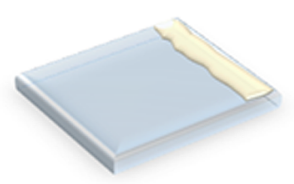

Dry mixture on PVA aligned glass at $52^{\circ} \mathrm{C}$

Polydispersity $=1.21$

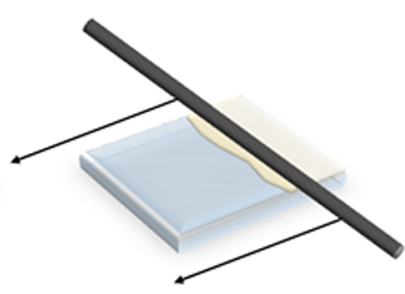

Coat with a wired bar

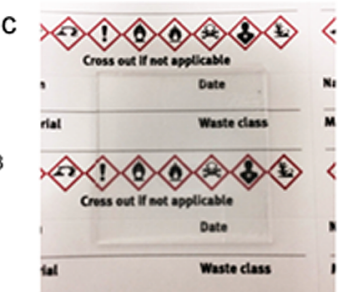

${ }^{a}$ The photo was slightly adjusted in brightness.
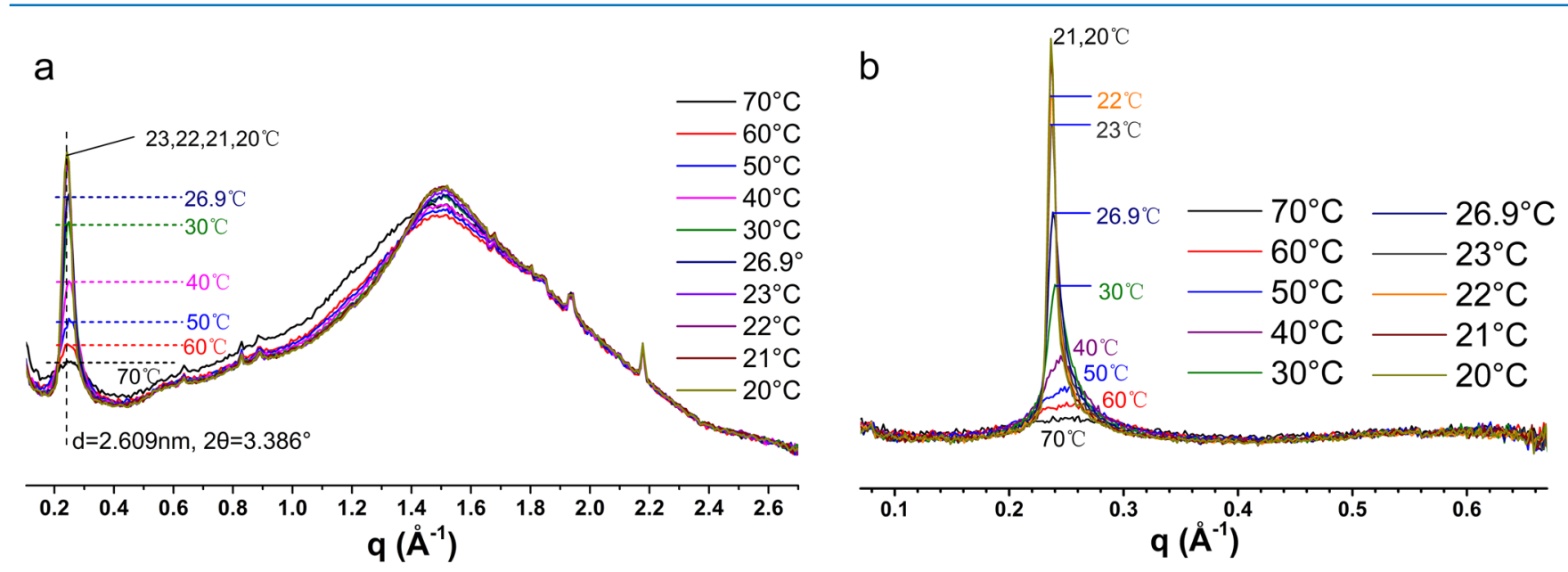

Figure 1. (a) WAXS and (b) SAXS of the HP-S811 mixture at different temperatures upon cooling.

determines the wavelength of reflection. ${ }^{21,22}$ This pitch can be modified in response to temperature, resulting in a change in the reflection wavelength. For CLCs that also have a smectic phase, large shifts of the reflection band have been reported at temperature changes just above the smectic to chiral nematic transition temperature. The transition to the smectic phase "unwinds" the helix as the smectic-cholesteric phase transition is approached, resulting in a red shift of the reflection band. $^{23-29}$ In this way, temperature-responsive reflective systems have been developed for various purposes..$^{10,25,30-34}$ Among them, a film made of a CLC elastomer shows reversible reflection band shifting by thermal deformation. ${ }^{35}$ However, in the fabrication methods to prepare these systems, the LC is brought into a narrow gap between two glass plates with alignment layers on the inside (an alignment cell), which limits their applications. Polymer-dispersed systems seem to be a good alternative for easier fabrication of temperature-responsive reflective coatings, ${ }^{36}$ but these have the tendency to be opaque due to the scattering of visible light. Easy procedures, such as knife coating, have been adopted for making static CLC color coatings $^{37}$ but never for responsive ones. As such, the development of a facile method to fabricate transparent temperature-responsive polymer IR-reflective coatings remains a challenge.

We now report on the fabrication of a temperatureresponsive IR-reflective coating using a simple wired-bar method. The photonic polymer film was based on a mixture of a side-chain liquid crystalline polysiloxane homopolymer $(\mathrm{HP})^{8,38,39}$ and $10 \%$ of chiral dopant S811 (Scheme 1), which has a $\mathrm{Sm}-\mathrm{N}^{*}$ phase transition. A $1000 \mathrm{~nm}$ reversible blue shift of the reflection band within the IR region was observed upon increasing the temperature from room temperature to $60{ }^{\circ} \mathrm{C}$. The same system in a cell showed a similar change of the reflection band as a function of temperature, but the coating showed a significantly faster response. These results show that easily processable responsive photonic coatings can be fabricated, which function similar to responsive systems in cells. The main advantage of using a coating is that it can be applied without the use of a glass cell. This is important because in many practical applications the use of a cell is not desirable or possible, such as for large, uneven, or curved surfaces. 


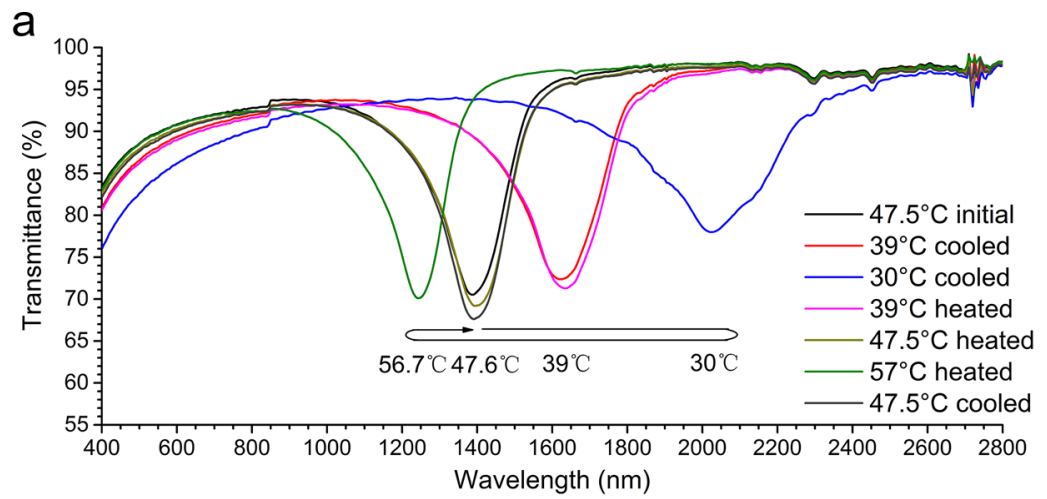

b
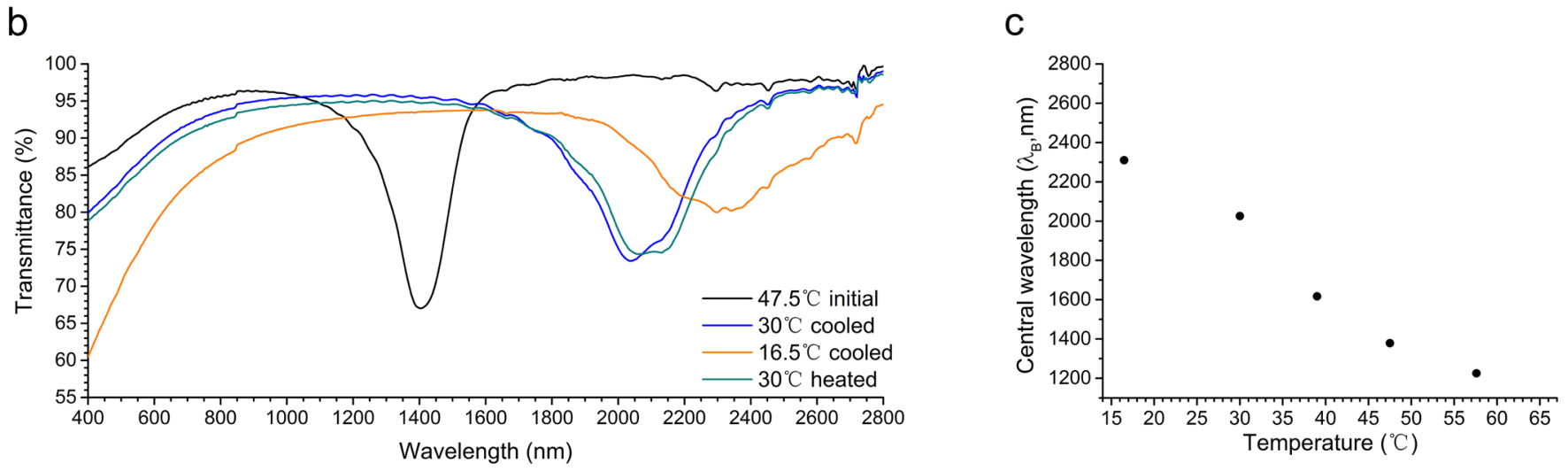

Figure 2. Transmission spectra of a single HP-S811 coating during two cycles of cooling and heating between (a) 56.7 and $30{ }^{\circ} \mathrm{C}$ and (b) 47.6 and $16.5^{\circ} \mathrm{C}$. (c) Reflection wavelength $\left(\lambda_{\mathrm{B}}\right)$ of the HP-S811 coating as a function of temperature.

\section{RESULTS AND DISCUSSION}

Preparation and Characterization of the LC Mixture. The side-chain liquid crystalline HP was synthesized by grafting an olefinic LC onto a polymethylhydrosiloxane (PMHS) backbone in the presence of Karstedt's catalyst. The structure of the HP was confirmed by attenuated total reflectance IR spectroscopy (ATR-IR, Figure S1), gel permeation chromatography (GPC), and proton nuclear magnetic resonance $\left({ }^{1} \mathrm{H}\right.$ NMR, Figure S2). The average degree of polymerization was 6.3 while the polydispersity was 1.21 (Table S1). Differential scanning calorimetry (DSC) revealed that the polymer has both the desired smectic and nematic phases (G-8 Sm 20.7 N 75 I, Figure S3).

An IR-reflecting chiral nematic LC mixture was created by adding $10 \mathrm{wt} \%$ chiral dopant S811 to the HP (Scheme 1), dissolving the mixture in dichloromethane (DCM), and evaporating the solvent overnight. The mixture had a cholesteric liquid crystalline phase between 22 and $64{ }^{\circ} \mathrm{C}$, an intermediate mesophase between -10 and $22{ }^{\circ} \mathrm{C}$, and glass transition at $-10{ }^{\circ} \mathrm{C}$. Wide-angle and small-angle X-ray scattering (WAXS and SAXS) measurements (Figure 1) showed a diffraction peak located at $q=0.24 \AA^{-1}(2 \theta=$ $\left.3.386^{\circ}, d=2.6 \mathrm{~nm}\right)$ at $\leq 60{ }^{\circ} \mathrm{C}$, which is a typical indication of the smectic order. The peak in the WAXS measurement at $q=$ $1.5 \AA^{-1}$ represents the side-by-side intermolecular spacing, which is present in both the nematic and smectic phases. When the smectic order is present in a nematic or cholesteric phase, this is known as a cybotactic structure. ${ }^{40,41}$ The existence of cybotactic structures in the entire cholesteric temperature range, combined with a peak intensity increase with decreasing temperature, reveals a gradual pretransitional effect of this system, indicating a gradual change from a cholesteric order to a smectic order.

Temperature Response of the HP-S811 Polymer Coating. The mixture of $\mathrm{HP}-\mathrm{S} 811$ was coated at $52{ }^{\circ} \mathrm{C}$ on a glass surface with a poly(vinyl alcohol) (PVA) alignment layer using a wired bar. After processing, a transparent colorless 11.5 $\mu \mathrm{m}$ thick coating was obtained (Scheme 1c). Polarizing optical microscopy (POM) analysis showed typical planar cholesteric textures (Figure S4). The stripes that were observed originated from the micro pattern of the coating bar and did not significantly influence coating transparency and properties.

The thermo-optical properties of the coating were investigated using ultraviolet-visible-IR (UV/vis/IR) spectroscopy. Figure 2 presents the stabilized transmission spectra of a coating at different temperatures in two heating and cooling cycles. The bandwidth of each reflection peak was calculated from full width at half-maximum (FWHM) reflection, and the Bragg reflection center $\left(\lambda_{\mathrm{B}}\right)$ was determined by the middle point of the FWHM line. The spectrum taken first at $47.5^{\circ} \mathrm{C}$ (Figure $2 \mathrm{a}, 47.5^{\circ} \mathrm{C}$ initial) had a reflection band centered at $\lambda_{\mathrm{B}}=\sim 1380 \mathrm{~nm}$. The reflection band had a trianglelike shape with a FWHM of $210 \mathrm{~nm}$. In the first cycle, between 56.7 and $30{ }^{\circ} \mathrm{C}$, the reflection band shifted from 1225 to 2026 $\mathrm{nm}$ (Figure 2a). In the second cycle, upon further cooling to $16.5^{\circ} \mathrm{C}$, the reflection band did not disappear but was centered at $2310 \mathrm{~nm}$ (Figure 2b). During the two cycles, the reflection band showed a reversible change as a function of temperature. Some scattering was also observed, which was visible as a lower transparency in the visible light region of the spectra. The scattering increased as the temperature decreased, and finally at $16.5^{\circ} \mathrm{C}$, below the $\mathrm{Sm}-\mathrm{N}^{*}$ transition point, scattering reached the highest degree. POM images displayed a new "fingerprint" texture at lower temperatures, indicating a homeotropic 
a

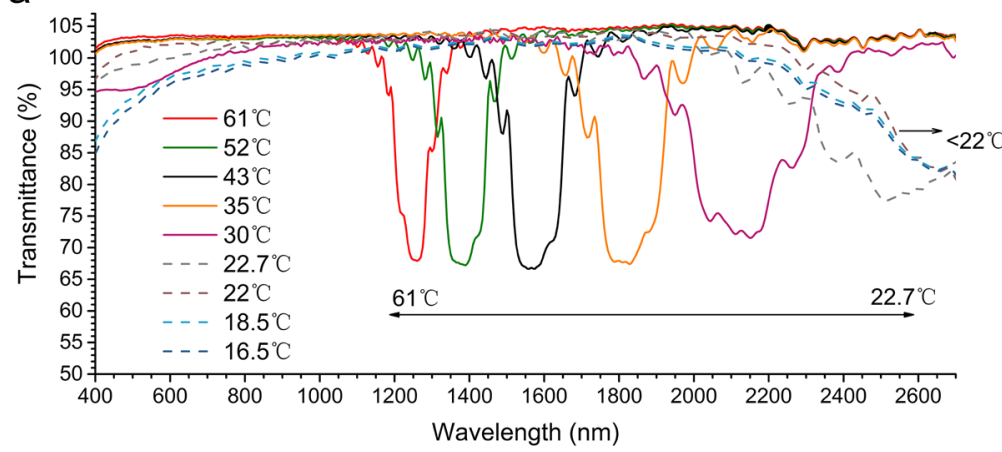

b

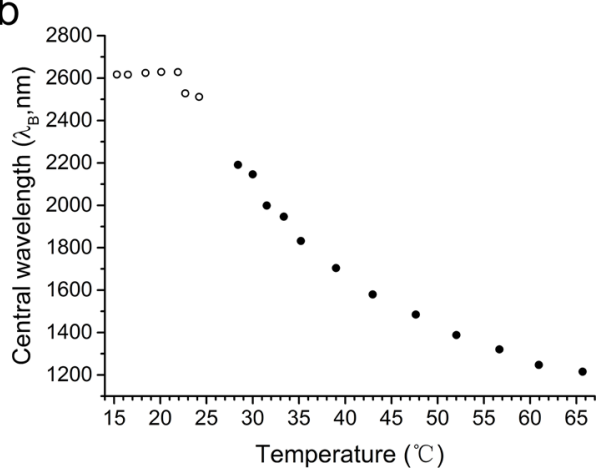

Figure 3. (a) Stabilized transmission spectra and (b) reflection wavelength $\left(\lambda_{\mathrm{B}}\right)$ of the HP-S811 cell as a function of temperature. The dashed lines and hollow dots refer to the spectral data partly out of the machine detection range.
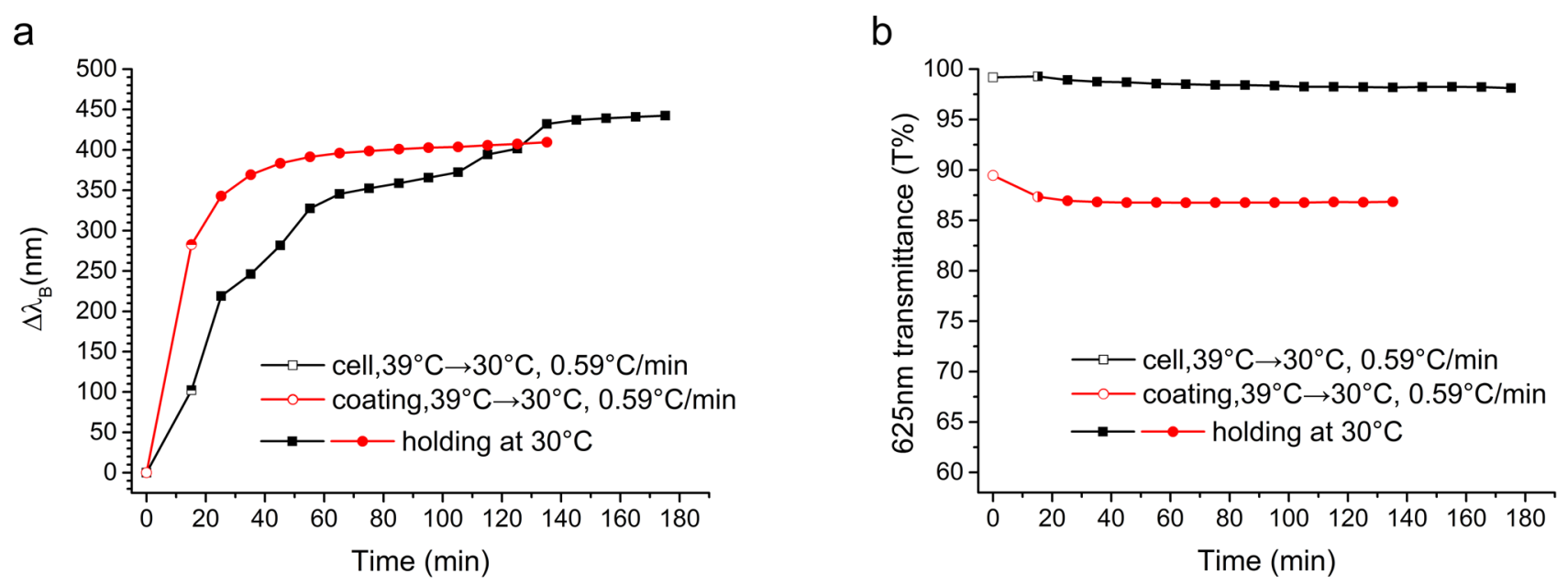

C
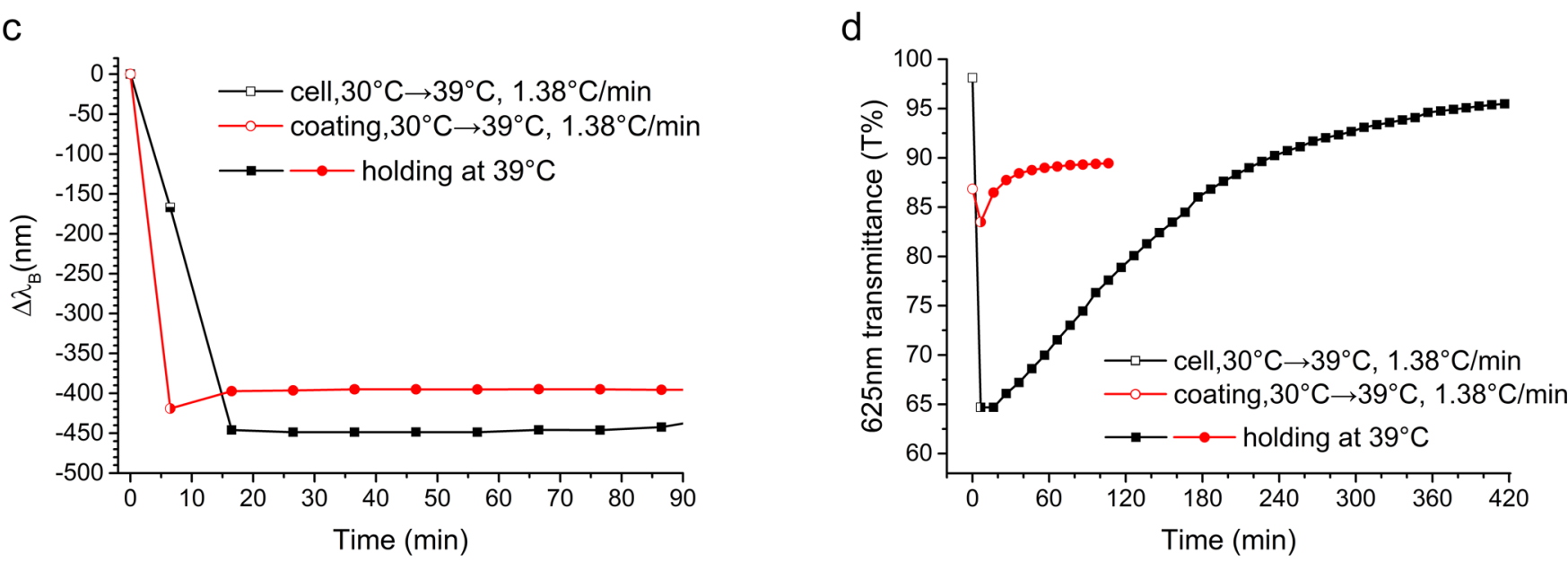

Figure 4. Response times of the HP-S811 cell and coating. (a) Change of the reflection band, $\Delta \lambda_{\mathrm{B}}$, and (b) change of the transmittance at $625 \mathrm{~nm}$ upon cooling from 39 to $30^{\circ} \mathrm{C}$. (c) Change of the reflection band, $\Delta \lambda_{\mathrm{B}}$, and (d) change of the transmittance at $625 \mathrm{~nm}$ upon heating from 30 to 39 ${ }^{\circ} \mathrm{C}$. Time zero is the status of the sample before cooling or heating. The open symbols describe the data points collected during the temperature ramp, and the solid symbols describe the data points collected once the temperature has stabilized.

alignment of the helices (Figure S4), which could account for the scattering of the coating. This homeotropic alignment of mesogens at the air-coating interface could be more favorable due to lower surface tensions. ${ }^{42,43}$ The fingerprint structure was more obvious on top of the planar textures when a coating surface was obtained by a $10 \mu \mathrm{m}$ narrow gap applicator (Figure S5). In another experiment, the temperature was raised beyond the cholesteric to isotropic transition point. This wiped out the alignment of the molecules as expected. When the temperature was then lowered back to the cholesteric range, the LCs realigned poorly and the coating became highly scattering. This should not hurt the practical application of the coating as it is meant to be used in the built environment, where such high temperatures should not be reached.

Temperature Response of the HP-S811 Cell. For comparison, the thermo-optic behavior of the HP-S811 
mixture was also studied in a cell. The spectrum of the cell exhibited an IR reflection peak centered at $\lambda_{\mathrm{B}}=1390 \mathrm{~nm}$ at 52 ${ }^{\circ} \mathrm{C}$ with a transmittance of $65 \%$. The cell was fully transparent in the visible region, indicating planar alignment of the LCs. Compared to that of the coating, the FWHM of this band was much smaller $(112 \mathrm{~nm})$, and its shape was not triangular. This can be explained by the absence of a fingerprint texture, which does not form due to the lack of an air interface and leads to a sharper band and less scattering. The temperature of the cell was varied between 66 and $16{ }^{\circ} \mathrm{C}$. Figure $3 \mathrm{a}$ shows the temperature-dependent reflection spectra measured after stabilization. The spectra show the same gradual change of the reflection center along the temperature range as was observed in the coating. In the CLC temperature range, a 1000 $\mathrm{nm}$ red shift of $\lambda_{\mathrm{B}}$ was observed, that is, $\lambda_{\mathrm{B}}$ increased from 1215 to $2190 \mathrm{~nm}$. This wavelength shift was fully reversible, as two heating and cooling cycles between 66 and $30^{\circ} \mathrm{C}$ showed the same behavior (Figure S6). Below the $\mathrm{Sm}-\mathrm{N}^{*}$ transition point $\left(22^{\circ} \mathrm{C}\right)$, the reflection bands were only partially visible due to light absorption of the glass cell but remained at the same position. This is similar to what was seen before in the coating.

Upon plotting the wavelength of the reflection band $\left(\lambda_{\mathrm{B}}\right)$ against temperature (Figure $3 \mathrm{~b}$ ), gradual reflection band shifts were observed. This behavior is different from the $\mathrm{Sm}-\mathrm{N}^{*}$ systems reported earlier, in which drastic reflection band shifting takes place within a few degrees of temperature. ${ }^{44}$ The gradual reflection band shift coincides with the gradual increase in the smectic order in the CLC phase, as observed by WAXS and SAXS (Figure 1). Most likely, as reported for other systems, this smectic order increase led to a gradual increase in pitch, leading to a red shift of the reflection band. ${ }^{45,46}$ Below the $\mathrm{Sm}-\mathrm{N}^{*}$ transition point, the reflection band was not changing, revealing that the pitch did not change at these temperatures. It should be noted that the slight decrease of the helical twisting power of chiral dopant S811 with decreasing temperature will only have a minor contribution to the gradual $\lambda_{\mathrm{B}}$ change. ${ }^{47,48}$

Response Time of the HP-S811 Cell and Coating. We studied the response time of the thermo-optical changes of the polymer LC mixture with respect to the reflection band shift and transparency changes. Figure 4 shows a comparison of the response of both the coating and cell upon cooling from 39 to $30{ }^{\circ} \mathrm{C}$ (Figure $4 \mathrm{a}, \mathrm{b}$ ) and heating from 30 to $39{ }^{\circ} \mathrm{C}$ (Figure $4 \mathrm{c}, \mathrm{d})$. Interestingly, the responsive behavior of the coating was different when compared to that of the cell. Upon cooling the cell, the shift of the reflection band took place over $160 \mathrm{~min}$ (Figure 4a), whereas the transparency of the cell did not change and stayed high (Figure $4 \mathrm{~b}$ ). In contrast, upon heating, the reflection band shifted in less than $10 \mathrm{~min}$ (Figure 4c), whereas the transparency initially dropped significantly due to scattering (from 98 to 65\%) and recovered only after $410 \mathrm{~min}$ (Figure $4 \mathrm{~d})$. For the coating, the shift of the reflection band was significantly faster upon cooling compared to that of the cell (60 vs $160 \mathrm{~min}$, Figure 4a), also without any drop in transparency (Figure 4b). Upon heating, the change of the reflection band was also faster compared to that in the cell ( 5 vs $10 \mathrm{~min}$, Figure 4c). The coating had a lower initial transparency compared to that of the cell, but upon heating, its transmittance dropped by only 5\% due to scattering (Figure 4d), and it quickly recovered in $20 \mathrm{~min}$. During heating, POM images of the coating (Figure S4) and the cell (Figure S7) showed the formation of focal conic textures, revealing a decrease in alignment. Even when heating at a very slow rate of $0.1{ }^{\circ} \mathrm{C} /$ min, this disorder was inevitable. At other temperatures, the effects were similar, and this data is summarized in Table S2. At lower temperatures, a longer time was needed to obtain a transparent cell in the visible region. To make sure that the difference in kinetics between the cell and the coating was not caused by a temperature difference, we measured the temperature during and after the ramp. The temperature of the cell and coating differed by less than $1{ }^{\circ} \mathrm{C}$ and vanished entirely after the ramp. This small temperature difference cannot be the cause for the large difference in kinetics that we observed.

On the Mechanism of the Temperature-Responsive IR-Reflective Cells and Coatings. The thickness of the coating $(11.5 \mu \mathrm{m})$ was shown to change only marginally with temperature (Figure S8). This reveals that the HP-S811 system undergoes helix winding and unwinding during pitch tuning without noticeable thermal expansion or shrinkage along the helical axis. The thickness in the cell is fixed by the cell gap; therefore, the response mechanism of the cell and coating should be similar. We argue that the faster response of the coating stems from the lack of a top alignment layer. In the cell, where the stronger anchoring force determines the alignment of the mesogens on both surfaces, helices can wind or unwind only by discontinuous jumps of integral $\pi$ rotations, ${ }^{49,50}$ which may set an energy barrier to pitch changing. In the coating, winding and unwinding of helices can take place without integer $\pi$ rotations and barriers are therefore removed, leading to a faster response. The scattering at intermediate temperatures is caused by the formation of focal conic defects. At a high temperature, the mixture has a low viscosity and the alignment, driven by the anchoring force of alignment layers, is fast. At a low temperature, where the helical pitch is long, planar alignment is thermodynamically favorable. ${ }^{24,51}$ However, at intermediate temperatures, neither is planar alignment favorable nor is the viscosity low enough to quickly recover the focal conic defects. Remarkably, the reflection band did not disappear upon going from the $\mathrm{N}^{*}$ to the $\mathrm{Sm}$ state, even though the temperature was still above $T_{\mathrm{g}}$. We assume that below the transition temperature the mixture system adopts a twist grain boundary (TGB A*) phase, an intermediate phase of transition where smectic clusters form a macroscopic spiraling layer structure, which possesses helical pitches as well. $^{52,53}$

\section{CONCLUSIONS}

In this article, a mixture consisting of an LC polysiloxane and the chiral dopant S811 has been prepared to fabricate an easily processable temperature-responsive IR-reflective coating. The photonic coating showed a blue shift in the reflection wavelength of light along a broad range in the IR region $(2350-1250 \mathrm{~nm})$ upon heating and was reversible. Interestingly, the response of the coating was considerably faster compared to that of the same material in a glass cell. This makes such a coating appealing as a temperature-responsive IR reflector that can autonomously regulate the temperature of indoor spaces. In the future, the reflection band of the coating can be fine-tuned to a different wavelength of IR by changing the amount of chiral dopant in the mixture.

Our research shows that side-chain LC polymers can be applied as coatable temperature-responsive IR-reflective films, opening up a promising route toward the development of smart windows that can be applied directly on various surfaces. Because the temperature and optical response mechanisms of 
the coating are similar to those of the cell, this reveals that other response mechanisms already reported for a cell can now also be applied to coatings, opening up new opportunities to fabricate temperature-responsive polymers with novel properties.

\section{METHODS}

Materials. 4-Hydroxybenzoic acid was purchased from J\&K Chemical (China). 6-Bromo-1-hexene was purchased from Heowns Biochem Technologies (China). 4-Methoxyphenol and dicyclohexylcarbodiimide were obtained from Adamas Reagent, Ltd. (China). 4-Dimethylaminopyridine was received from Shanghai Macklin Biochemical Co., Ltd. (China). PMHS (trimethylsilyl-terminated, average $\mathrm{Mn} \sim 390$ ), platinum(0)-1,3divinyl-1,1,3,3-tetramethyldisiloxane complex solution in $\mathrm{xy}$ lene, $\mathrm{Pt} \sim 2 \%$ (Karstedt's catalyst), and anhydrous toluene were purchased from Sigma-Aldrich. Chiral dopant S811 was bought from Jiangsu Hecheng Advanced Materials Co., Ltd. (China). All materials were used as received without further purification.

Characterization. The compounds were characterized by ATR-IR (Bruker VERTEX 70) and by ${ }^{1} \mathrm{H}$ NMR (Varian AS400; $400 \mathrm{MHz}$ ) using chloroform- $d$. The HP was analyzed by a GPC (Waters e2695) system equipped with a refractive index detector (Waters 2414) using tetrahydrofuran as eluent and monodisperse polystyrene calibration standards. Phase transition temperatures of the HP were measured by DSC (Mettler Toledo DSC 1) using heating and cooling rates of 2 ${ }^{\circ} \mathrm{C} / \mathrm{min}$. The mixture was analyzed by both WAXS and SAXS (Ganesha lab instrument) at various temperatures. Optical textures of the cells and coatings were investigated by POM (Leica DM 7200P or Leica DM 2700M) with a hot stage (Linkam PE95/T95). Transmission spectra of the cells and coatings were obtained with a UV/vis/NIR spectrometer (PerkinElmer Lambda 950) with a two-dimensional detector module. The temperature of the sample was controlled by a water-agent temperature controller (EYELA NCB-1200) and was calibrated by a thermoelectric couple. The thickness of the coating was measured by an interferometer (Forgale Zoomsurf 3D).

Preparation of HP. The HP was synthesized by grafting olefinic LC 4-methoxyphenyl 4-(5-hexenyloxy) benzoate onto a polymethylhydrosiloxane backbone in the presence of Karstedt's catalyst as previously reported. ${ }^{54,55}$ A detailed synthetic procedure and characterization can be found in the Supporting Information.

Preparation of the CLC Polysiloxane Mixture. The HP (205.8 mg) and chiral dopant S811 (22.9 mg, $10 \mathrm{wt} \%)$ were dissolved in DCM. The solvent was slowly evaporated on a 55 ${ }^{\circ} \mathrm{C}$ hot plate and further removed in high vacuum at $70{ }^{\circ} \mathrm{C}$ overnight to yield a homogenous polysiloxane-chiral dopant mixture.

Fabrication of the IR-Reflective Coatings. A few drops of a $5.0 \mathrm{wt} \%$ PVA in aqueous solution were spin-coated onto 3 $\times 3 \mathrm{~cm}^{2}$ clean glass plates at $2000 \mathrm{rpm}$ for $30 \mathrm{~s}$. The deposited films were dried at $60.0{ }^{\circ} \mathrm{C}$ for about $1 \mathrm{~h}$ and subsequently rubbed on a velvet textile cloth in one direction to induce alignment. The glass plate with the PVA alignment layer was then placed on a hot plate at $52{ }^{\circ} \mathrm{C}$. A coating bar having a surface microstructure with a waviness height of $24.4 \mu \mathrm{m}$ and a wavelength of $202.6 \mu \mathrm{m}$ was heated to $52{ }^{\circ} \mathrm{C}$. The LC mixture was put on one side of the glass plate and coated by the bar in the direction antiparallel to the PVA layer rubbing direction. The bar was moved over the plate several times until the material was fully covering the plate. The resulting coating was stored on the hot plate at $52{ }^{\circ} \mathrm{C}$. The coating in Figure S5 was obtained using a narrow gap applicator instead of the rod.

Preparation of IR-Reflective Cells. Two of the glass plates with the rubbed PVA alignment layer were imposed antiparallel on each other and glued together using a UV glue containing $15 \mu \mathrm{m}$ silica particles as spacers. The mixture was filled into the cell at $52{ }^{\circ} \mathrm{C}$ by capillary forces.

\section{ASSOCIATED CONTENT}

\section{Supporting Information}

The Supporting Information is available free of charge on the ACS Publications website at DOI: 10.1021/acsomega.7b00454.

Synthetic route of M1 and HP; measurement methods; characterization of HP by ATR-IR and ${ }^{1} \mathrm{H}$ NMR; DSC curve of $\mathrm{HP}$ and $\mathrm{HP}-\mathrm{S} 811$ mixture; temperaturedependent POM images of both the cell and the coating; stabilized UV/vis/NIR spectra of the cell in both the cooling and heating cycles; the response time of the cell and the coating in all heating and cooling ramps; and thickness of the coating by temperature (PDF)

\section{AUTHOR INFORMATION}

\section{Corresponding Authors}

*E-mail: ldhaan@guohua-oet.com (L.T.D.H.).

*E-mail: guofu.zhou@m.scnu.edu.cn (G.Z.).

ORCID

Albertus P. H. J. Schenning: 0000-0002-3485-1984

Notes

The authors declare no competing financial interest.

\section{ACKNOWLEDGMENTS}

The authors like to acknowledge Dick Broer, Michael Debije, and Danqing Liu for scientific discussions. This work was financially supported by the National Natural Science Foundation of China (Nos. 51561135014, U1501244, and 2161101058), Guangdong Innovative Research Team Program (No. 2013C102), Major Science and Technology Projects of Guangdong Province (No. 2015B090913004), the 111 Project, and Top-Notch Graduate Foundation of South China Normal University (No. 2016009).

\section{REFERENCES}

(1) Yang, W.; Runnerstrom, E. L.; Milliron, D. J. Switchable Materials for Smart Windows. Annu. Rev. Chem. Biomol. Eng. 2016, 7, 283.

(2) Khandelwal, H.; Loonen, R. C. G. M.; Hensen, J. L. M.; Schenning, A. P. H. J.; Debije, M. G. Application of broadband infrared reflector based on cholesteric liquid crystal polymer bilayer film to windows and its impact on reducing the energy consumption in buildings. J. Mater. Chem. A 2014, 2, 14622.

(3) Khandelwal, H.; Roberz, F.; Loonen, R. C. G. M.; Hensen, J. L. M.; Bastiaansen, C. W. M.; Broer, D. J.; Debije, M. G.; Schenning, A. P. H. J. Infrared reflector based on liquid crystal polymers and its impact on thermal comfort conditions in buildings. Proc. SPIE 2014, No. 91820 S.

(4) Loonen, R. C. G. M.; Trčka, M.; Cóstola, D.; Hensen, J. L. M. Climate adaptive building shells: State-of-the-art and future challenges. Renewable Sustainable Energy Rev. 2013, 25, 483-493.

(5) Riley, C. T.; Smalley, J. S. T.; Brodie, J. R. J.; Fainman, Y.; Sirbuly, D. J.; Liu, Z. W. Near-perfect broadband absorption from hyperbolic metamaterial nanoparticles. Proc. Natl. Acad. Sci. U.S.A. 2017, 114, $1264-1268$. 
(6) Khandelwal, H.; Schenning, A. P. H. J.; Debije, M. G. Infrared Regulating Smart Window Based on Organic Materials. Adv. Energy Mater. 2017, No. 1602209.

(7) Calculated from the data given at the website of National Research Energy Laboratory. http://www.nrel.gov.

(8) Finkelmann, H.; Rehage, G. Investigations on Liquid-Crystalline Polysiloxanes. 2. Optical-Properties of Cholesteric Phases and Influence of the Flexible Spacer on the Mobility of the Mesogenic Groups. Makromol. Chem., Rapid Commun. 1980, 1, 733-740.

(9) Yamagishi, T.-A.; Sixou, P. Preparation and characteristics of cholesteric gel from pentyl ether of hydroxypropyl cellulose. Polymer 1995, 36, 2315-2317.

(10) Tzeng, S. Y. T.; Chen, C. N.; Tzeng, Y. Thermal tuning band gap in cholesteric liquid crystals. Liq. Cryst. 2010, 37, 1221-1224.

(11) Kawaguchi, H. Thermoresponsive microhydrogels: preparation, properties and applications. Polym. Int. 2014, 63, 925-932.

(12) Yue, Y. F.; Haque, M. A.; Kurokawa, T.; Nakajima, T.; Gong, J. P. Lamellar hydrogels with high toughness and ternary tunable photonic stop-band. Adv. Mater. 2013, 25, 3106-3110.

(13) Yoon, J.; Lee, W.; Thomas, E. L. Thermochromic block copolymer photonic gel. Macromolecules 2008, 41, 4582-4584.

(14) Sussman, J.; Snoswell, D.; Kontogeorgos, A.; Baumberg, J. J.; Spahn, P. Thermochromic polymer opals. Appl. Phys. Lett. 2009, 95, No. 173116.

(15) Pursiainen, O. L.; Baumberg, J. J.; Winkler, H.; Viel, B.; Spahn, P.; Ruhl, T. Nanoparticle-tuned structural color from polymer opals. Opt. Express 2007, 15, 9553-61.

(16) Valkama, S.; Kosonen, H.; Ruokolainen, J.; Haatainen, T.; Torkkeli, M.; Serimaa, R.; Ten Brinke, G.; Ikkala, O. Self-assembled polymeric solid films with temperature-induced large and reversible photonic-bandgap switching. Nat. Mater. 2004, 3, 872-876.

(17) Seeboth, A.; Lotzsch, D.; Ruhmann, R.; Muehling, O. Thermochromic Polymers-Function by Design. Chem. Rev. 2014, 114, 3037-3068.

(18) Stumpel, J. E.; Broer, D. J.; Schenning, A. P. Stimuli-responsive photonic polymer coatings. Chem. Commun. 2014, 50, 15839-15848.

(19) Ueno, K.; Matsubara, K.; Watanabe, M.; Takeoka, Y. An electroand thermochromic hydrogel as a full-color indicator. Adv. Mater. 2007, 19, 2807-2812.

(20) Chiappelli, M. C.; Hayward, R. C. Photonic multilayer sensors from photo-crosslinkable polymer films. Adv. Mater. 2012, 24, 61006104.

(21) Stegemeyer, H.; Mueller, W. U.; Mainusch, K. J.; Finkelmann, H. Selective light reflection on cholesteric liquid crystals. Arch. Eisenhuettenwes. 1975, 46, 609-614.

(22) Eelkema, R.; Feringa, B. L. Amplification of chirality in liquid crystals. Org. Biomol. Chem. 2006, 4, 3729-3745.

(23) Zhang, L. P.; Wang, M.; Wang, L.; Yang, D. K.; Yu, H. F.; Yang, $\mathrm{H}$. Polymeric infrared reflective thin films with ultra-broad bandwidth. Liq. Cryst. 2016, 43, 750-757.

(24) Wang, F. F.; Cao, H.; Li, K. X.; Song, P.; Wu, X. J.; Yang, H. Control homogeneous alignment of chiral nematic liquid crystal with smectic-like short-range order by thermal treatment. Colloids Surf., A 2012, 410, 31-37.

(25) Yang, H.; Yamane, H.; Kikuchi, H.; Yamane, H.; Zhang, G.; Chen, X.; Tisato, K. Investigation of the electrothermo-optical effect of a smectic LCP-nematic LC-chiral dopant ternary composite system based on SA $\leftrightarrow \mathrm{N}^{*}$ phase transition. J. Appl. Polym. Sci. 1999, 73, 623-631.

(26) Zhang, F.; Yang, D. K. Temperature dependence of pitch and twist elastic constant in a cholesteric to smectic A phase transition. Liq. Cryst. 2002, 29, 1497-1501.

(27) de Gennes, P. G. An analogy between superconductors and smectics A. Solid State Commun. 1972, 10, 753-756.

(28) Goodby, J. W.; Waugh, M. A.; Stein, S. M.; Chin, E.; Pindak, R.; Patel, J. S. A New Molecular Ordering in Helical Liquid-Crystals. J. Am. Chem. Soc. 1989, 111, 8119-8125.
(29) Dierking, I.; Gießelmann, F.; Zugenmaier, P. TGB A* state in a homologous series of diarylethane $\alpha$-chloroester ferroelectric liquid crystals. Liq. Cryst. 1994, 17, 17-22.

(30) Vijayaraghavan, R. K.; Abraham, S.; Akiyama, H.; Furumi, S.; Tamaoki, N.; Das, S. Photoresponsive glass-forming butadiene-based chiral liquid crystals with circularly polarized photoluminescence. $A d v$. Funct. Mater. 2008, 18, 2510-2517.

(31) Wu, X. J.; Cao, H.; Guo, R. W.; Li, K. X.; Wang, F. F.; Yang, H. Effect of cholesteric liquid crystalline elastomer with binaphthalene crosslinkings on thermal and optical properties of a liquid crystal that show smectic A-cholesteric phase transition. Polym. Adv. Technol. 2013, 24, 228-235.

(32) Huang, W.; Zhang, X. G.; Guo, J. B.; Zhang, L. P.; Bian, Z. Y.; Zhao, D. Y.; He, W. L.; Cao, H.; Yang, H. Super wide-band reflective polarisers from polymer stabilised liquid crystal films. Liq. Cryst. 2009, 36, 497-501.

(33) Yang, H.; Kikuchi, H.; Kajiyama, T. Thermal switching characteristics based on smectic-A↔chiral nematic phase transitions of (liquid crystals/chiral dopant) composites, with and without side chain-type liquid crystalline polymer. Liq. Cryst. 2002, 29, 1141-1149.

(34) Jian, S.; Huihui, W.; Ling, W.; Hui, C.; Hui, X.; Xueyao, L.; Jiumei, X.; Hangiun, D.; Zhou, Y.; Huai, Y. Preparation and thermooptical characteristics of a smart polymer-stabilized liquid crystal thin film based on smectic A-chiral nematic phase transition. Smart Mater. Struct. 2014, 23, No. 125038.

(35) Nagai, H.; Urayama, K. Thermal response of cholesteric liquid crystal elastomers. Phys. Rev. E: Stat., Nonlinear, Soft Matter Phys. 2015, 92, No. 022501.

(36) Hakemi, H. Industrial Development of Plastic PDLC: Is There a Future? Liq. Cryst. Today 1998, 8, 7-12.

(37) Korenic, E. M.; Jacobs, S. D.; Faris, S. M.; Li, L. Cholesteric Liquid Crystal Flakes - A New Form of Domain. Mol. Cryst. Liq. Cryst. Sci. Technol., Sect. A 1998, 317, 197-219.

(38) Finkelmann, H.; Rehage, G. Liquid-Crystal Side-Chain Polymers. Macromol. Chem. Phys. 1984, 6, 29.

(39) Wang, J. W.; Zhang, B. Y. Synthesis and properties of novel chiral side-chain liquid crystalline polysiloxanes containing different chiral pendant groups. J. Mater. Sci. 2014, 49, 604-613.

(40) Davidson, P. X-ray diffraction by liquid crystalline side-chain polymers. Prog. Polym. Sci. 1996, 21, 893-950.

(41) Becker, P.; Siebert, H.; Noirez, L.; Schmidt, C. Shear-induced order in nematic polymers. Macromol. Symp. 2005, 220, 111-122.

(42) Agez, G.; Bitar, R.; Mitov, M. Color selectivity lent to a cholesteric liquid crystal by monitoring interface-induced deformations. Soft Matter 2011, 7, 2841-2847.

(43) Nagano, S. Inducing Planar Orientation in Side-Chain LiquidCrystalline Polymer Systems via Interfacial Control. Chem. Rec. 2016, $16,378-392$.

(44) Natarajan, L. V.; Wofford, J. M.; Tondiglia, V. P.; Sutherland, R. L.; Koerner, H.; Vaia, R. A.; Bunning, T. J. Electro-thermal tuning in a negative dielectric cholesteric liquid crystal material. J. Appl. Phys. 2008, 103, No. 093107.

(45) Suresh, K. A.; Chandrasekhar, S. Optical and X-Ray Studies on Twisted Smectic-C and Twisted Nematic Phases - Evidence for a Skew-Cybotactic Type of Cholesteric Structure. Mol. Cryst. Liq. Cryst. 1977, 40, 133-141.

(46) Mallia, V. A.; Tamaoki, N. Study of chiral dimesogens: Liquid crystalline properties, effect of smectic cybotactic domains in controlling the chiral reflections and glassy liquid crystal forming properties. Mol. Cryst. Liq. Cryst. 2006, 454, 81-90.

(47) Huang, Y.; Zhou, Y.; Doyle, C.; Wu, S. T. Tuning the photonic band gap in cholesteric liquid crystals by temperature-dependent dopant solubility. Opt. Express 2006, 14, 1236-42.

(48) Shim, K. S.; Heo, J. U.; Jo, S. I.; Lee, Y. J.; Kim, H. R.; Kim, J. H.; Yu, C. J. Temperature-independent pitch invariance in cholesteric liquid crystal. Opt. Express 2014, 22, 15467-72.

(49) Dierking, I.; Gießelmann, F.; Zugenmaier, P.; Kuczynskit, W.; Lagerwall, S. T.; Stebler, B. Investigations of the structure of a cholesteric phase with a temperature induced helix inversion and of the 
succeeding Sc* phase in thin liquid crystal cells. Liq. Cryst. 1993, 13, $45-55$.

(50) Yoon, H. G.; Dierking, I.; Gleeson, H. F. Cholesteric pitch divergence near smectic phase transitions. Phys. Rev. E: Stat., Nonlinear, Soft Matter Phys. 2010, 82, No. 011705.

(51) Zhang, F.; Yang, D. K. Evolution of disclinations in cholesteric liquid crystals. Phys. Rev. E: Stat., Nonlinear, Soft Matter Phys. 2002, 66, No. 041701.

(52) Chilaya, G. Always Cholesterics ... but Sometimes Chiral Smectic C, TGB and Blue Phases. Mol. Cryst. Liq. Cryst. 2012, 561, 835 .

(53) Chilaya, G. S. Effect of various external factors and pretransitional phenomena on structural transformations in cholesteric liquid crystals. Crystallogr. Rep. 2000, 45, 871-886.

(54) Stevens, H.; Rehage, G.; Finkelmann, H. Phase-Transformations of Liquid-Crystalline Side-Chain Oligomers. Macromolecules 1984, 17, $851-856$.

(55) Ringsdorf, H.; Schneller, A. Liquid-Crystalline Side-Chain Polymers with Low Glass-Transition Temperatures. Makromol. Chem., Rapid Commun. 1982, 3, 557-562. 